Thorax (1975), 30, 337.

\title{
Evaluation of breath holding in hypercapnia as a simple clinical test of respiratory chemosensitivity
}

\author{
N. N.S T A N L E Y ${ }^{1}, E$. L. C U N N I N G H A M, \\ M. D. A L T O S E, S. G.K E L S E N, R. S. L E V I N S O N, \\ a n d N. S. C H E R N I A C K \\ Cardiovascular-Pulmonary Division, Department of Medicine, University of Pennsylvania School \\ of Medicine, Philadelphia, Pennsylvania 19104, USA
}

\begin{abstract}
Stanley, N. N., Cunningham, E. L., Altose, M. D., Kelsen, S. G., Levinson, R. S., and Cherniack, N. S. (1975). Thorax, 30, 337-343. Evaluation of breath holding in hypercapnia as a simple clinical test of respiratory chemosensitivity. Breath holding was used as the basis of a simple test of respiratory chemosensitivity. Breath holding was begun at selected degrees of hypercapnia produced by $\mathrm{CO}_{2}$ rebreathing. In 16 healthy control subjects there was a linear regression of the log of breath-holding time on the $\mathrm{PCO}_{2}$ at the start of breath holding. Breath-holding time (BHT) and the slope of a log $\mathrm{BHT} / \mathrm{PCO}_{2}$ plot were closely correlated with the ventilatory response to $\mathrm{CO}_{2}$. In five cases of the idiopathic hypoventilation syndrome, $\mathrm{CO}_{2}$ retention and reduced ventilatory response to $\mathrm{CO}_{2}$ were accompanied by prolonged breath-holding time and the regression of $\log \mathrm{BHT}$ on $\mathrm{PCO}_{2}$ was abnormally flat. However, in 17 patients with chronic airways obstruction, breath-holding time was never prolonged and the $\log \mathrm{BHT} / \mathrm{PCO}_{2}$ relationship was normal, even though 13 had a diminished ventilatory response to $\mathrm{CO}_{2}$ and four had chronic $\mathrm{CO}_{2}$ retention. It is concluded that the $\mathrm{BHT} / \mathrm{PCO}_{2}$ relationship provides a useful index of respiratory chemosensitivity which is not influenced by airways obstruction. This may be helpful in the detection of impaired chemosensitivity as a cause of $\mathrm{CO}_{2}$ retention even when the ventilation $\mathrm{CO}_{2}$ response is reduced non-specifically by coexisting airways obstruction.
\end{abstract}

Chronic $\mathrm{CO}_{2}$ retention is most frequently due to chronic airways obstruction which hinders the translation of respiratory motor activity into ventilation. Another important cause of chronic hypercapnia is impairment of respiratory chemosensitivity as in the idiopathic hypoventilation syndrome. The recognition of impaired chemosensitivity in cases of this syndrome is sometimes made difficult by the coexistence of chronic airways obstruction (McNicol and Pride, 1965; Rhoads and Brody, 1969). Respiratory chemosensitivity is usually measured by the increment in ventilation elicited by a change in the alveolar or arterial $\mathrm{CO}_{2}$ tension produced by breathing a $\mathrm{CO}_{2}$ enriched gas mixture. However, the ventilatory response to $\mathrm{CO}_{2}$ is altered if ventilation is obstructed even when respiratory chemosensitivity is normal (Cherniack and Snidal, 1956). This has stimulated a search for other tests of respiratory

${ }^{1}$ Present address: Department of Medicine, The Middlesex Hospital, London W1P 7PN chemosensitivity which are not affected by mechanical factors (Brodovsky, Macdonell, and Cherniack, 1960; Milic-Emili and Tyler, 1963; Lourenço et al., 1966).

Breath-holding time (BHT) has an inverse relationship with the alveolar $\mathrm{CO}_{2}$ tension $\left(\mathrm{PCO}_{2}\right)$ at the start of a breath hold (Hill and Flack, 1908; Godfrey and Campbell, 1969), which suggests that the $\mathrm{BHT} / \mathrm{PCO}_{2}$ relationship may provide an index of respiratory chemosensitivity. Moreover, observations by others in healthy subjects breathing through resistances have suggested that the BHT/PCo, relationship is insensitive to airway obstruction (Clark and Godfrey, 1969). The present study examines whether breath-holding time might provide a useful test of chemosensitivity in the presence of chronic airways obstruction.

\section{METHODS}

Measurements were made of breath-holding time at different $\mathrm{PCO}_{2}$ levels and of the ventilatory 
response to $\mathrm{CO}_{2}$ (ventilation $\mathrm{CO}_{2}$ response) in 16 healthy control subjects. These data served two purposes: (a) they determined whether breathholding time was correlated with the ventilation $\mathrm{CO}_{2}$ response in subjects without airway obstruction, and $(b)$ they were used to construct a normal range for the $\mathrm{BHT} / \mathrm{PCO}_{2}$ relationship. In addition, these measurements were obtained in 22 patients: 17 were obtained randomly from hospital inpatients and outpatients referred for evaluation of chronic airways obstruction to the pulmonary function laboratory. The five other patients were a specially selected group with persistent hypercapnia due to the idiopathic hypoventilation syndrome; four of these also had mild airway obstruction, but severe depression of respiratory chemosensitivity had been established by demonstrating grossly diminished $\mathrm{CO}_{2}$ responsiveness of the diaphragm electromyogram (Lourenço and Miranda, 1968).

APPARATUS In all patients the forced expiratory volume in one second $\left(F E V_{1}\right)$ and forced vital capacity (FVC) were obtained by standard techniques (Kory et al., 1961) using a low-resistance spirometer (Warren E. Collins, Model P-1300). Residual volume (RV) and total lung capacity (TLC) were measured by the helium dilution method (Boren, Kory, and Syner, 1966). Arterial $\mathrm{PO}_{2}, \mathrm{PCO}_{2}$, and $\mathrm{pH}$ were measured by appropriate electrodes (Radiometer, E5046/E5036/PHM71), and the serum bicarbonate was calculated from the $\mathrm{PCO}_{2}$ and $\mathrm{pH}$ values using the SiggaardAndersen nomogram (1963).

Measurements of the ventilation $\mathrm{CO}_{2}$ response in the patients and control subjects were made while they rebreathed through a heated pneumotachograph (Fleisch No. 2, Instrumentation Associates) from a rubber bag containing about 6 litres of $6-8 \%$ in oxygen. The initial $\mathrm{CO}_{2}$ concentration in the bag was adjusted to be approximately equivalent to the subject's mixed venous $\mathrm{PCO}_{2}$, which was assumed to be $0.198 \mathrm{kPa}(6 \mathrm{mmHg})$ more than the arterial $\mathbf{P C O}_{2}$. The pressure difference across the pneumotachograph was measured by a differential pressure transducer (Statham PM-5) to monitor airflow. Gas was continuously sampled at the mouth for the measurement of end-tidal $\mathrm{CO}_{2}$ concentration by an infrared analyzer (Godart Capnograph). The signals of airflow and $\mathrm{CO}_{2}$ concentration were displayed on a multichannel recorder (Electronics for Medicine, DR-12); the airflow signal was also electronically integrated to provide a continuous record of tidal volume.
EXPERIMENTAL PROCEDURE Two practice breath $\overrightarrow{\vec{p}}$ holds were made after room air breathing anф then the subject began to rebreathe from the rubber bag. Within a few breaths the $\mathrm{CO}_{2}$ con $\frac{\bar{m}}{5}$ centration equilibrated within the bag and the subject's lungs, and after this the first test breatiw hold was made. Following this the subject rested for five minutes and a second test breath hold was performed after another period of rebreathing ha‡ raised the alveolar $\mathrm{PCO}_{2}$ to at least $0.665 \mathrm{kP}$ $(5 \mathrm{mmHg})$ more than the level at the start of the first test breath hold. In the control subjects the procedure was repeated several times so thaf several breath holds were made at different deis grees of hypercapnia. All breath holds were made् after full inspiration. Each breath hold was evalue ated by measuring the end-tidal $\mathrm{PCO}_{2}$ immediately before each breath hold and also the breathe holding time. The $\mathrm{BHT} / \mathrm{PCO}_{2}$ relationship waฐ then assessed by plotting breath-holding timeagainst initial $\mathrm{PCO}_{2}$. Ventilation was also recordef్f during a rebreathing period which was not interrupted by breath holding. The ventilation $\mathrm{CO}_{0}$ response was assessed by plotting ventilatio measured over five breath intervals against the $\mathrm{PCO}_{2}$ at the mid-point of each interval.

\section{RESULTS}

CONTROL SUBJECTS

RELATIONSHIPS OF VENTILATION AND BREATH HOLdING TIME WITH $\mathrm{PCO}_{2}$ These are illustrated in Fig. 1 using the data obtained in a representag tive subject. Ventilation was plotted again ${ }^{9}$ $\mathrm{PCO}_{2}$ during uninterrupted rebreathing (Fig. $1 \mathrm{Ag}$ and breath-holding time against the initial $\mathrm{PCO}_{2}$ of six breath holds made at different levels of hype capnia (Fig. 1B). Ventilation increased linear with alveolar $\mathrm{PCO}_{2}$ during rebreathing, as pre viously described (Read and Leigh, 1967), and sq the relationship between ventilation (Ve) an $\mathrm{PCO}_{2}$ could be expressed by the well-knowis equation $\dot{\mathrm{V}} \mathrm{e}=\mathrm{S}\left(\mathrm{PCO}_{2}-\mathrm{B}\right)$ where $\mathrm{S}$ is the slope of the ventilation- $-\mathrm{PCO}_{2}$ line and $\mathrm{B}$ is its intercept with the $\mathrm{PCO}_{2}$ axis. Since $\mathrm{Ve}$ and $\mathrm{PCO}_{2}$ were linearty related, the value of $S$ was constant at all levels $\mathrm{PCO}_{2}$ and provided a satisfactory measure of the ventilatory response to $\mathrm{CO}_{2}$. In contrast, breat holding time had an inverse and curvilinear relationship with $\mathrm{PCO}_{2}$ (Fig. 1B). Thus, white isolated measurements of breath-holding time could be related to the degree of the $\mathrm{PCO}_{2}$ stimulus, the decrement of breath-holding time produced by a given increment of $\mathrm{PCO}_{2}$ was not constane The relationship was linear when breath-holding 

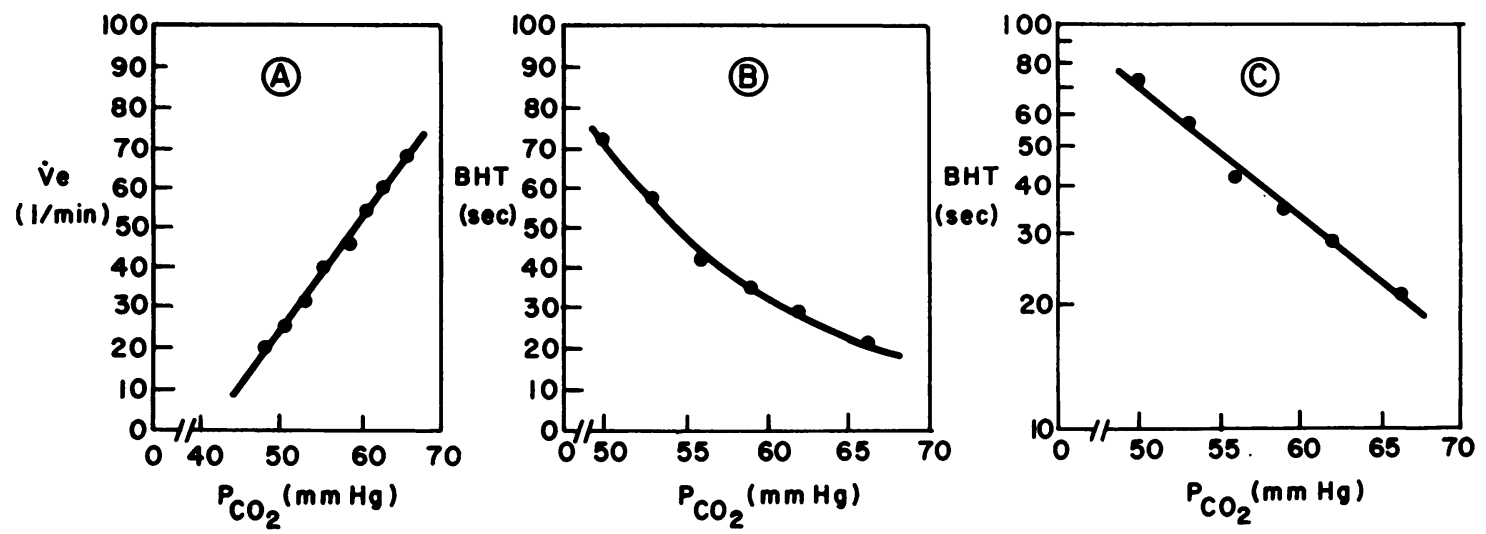

FIG. 1. Relationship between ventilation $(\dot{V} e)$ and breath-holding time $(B H T)$ and alveolar $\mathrm{PCO}_{2}$ in a healthy subject: $(A)$ ventilation and $\mathrm{PCO}_{2}$ are linearly related; $(B)$ the plot of $B H T$ against the $\mathrm{PCO}_{2}$ at the start of breath holding is curvilinear; (C) the $\mathrm{BHT} / \mathrm{PCO}_{2}$ relationship is linearized when drawn on semi-logarithmic paper. Conversion: Traditional units to $\mathrm{SI}-\mathrm{PCO}_{2}: 1 \mathrm{mmHg} \approx 7.5 \mathrm{kPa}$.

time was plotted on a logarithmic scale (Fig. 1C). The regression of breath-holding time on $\mathrm{PCO}^{2}$ could therefore be expressed in the form $\mathrm{BHT}=\mathrm{a} \cdot 10^{\mathrm{bPCO}}{ }_{2}$ where $b$ represents the slope of the $\mathrm{BHT} / \mathrm{PCO}_{2}$ line on semilogarithmic paper and $a$ is the intercept at zero $\mathrm{PCO}_{2}$. The slope of the regression line may be more simply described by the increment in $\mathrm{PCO}_{2}\left(\mathrm{APCO}_{2}\right)$ required to halve the breath-holding time. This halving $\Delta \mathrm{PCO}_{2}$ is reciprocally related to the slope of the log $\mathrm{BHT} / \mathrm{PCO}_{2}$ line; it is independent of the $\mathrm{PCO}_{2}$ range under consideration and its use is analogous to the description of the rate of an exponential decay curve by means of its half-time.

CORRELATION BETWEEN $\mathrm{CO}_{2}$ RESPONSIVENESS OF VENTILATION AND BHT The slopes of the ventilation $\mathrm{CO}_{2}$ response lines (SVR) ranged from 11.25 to $46.51 \mathrm{~min}^{-1} \mathrm{kPa}^{-1}$ (1.5 to $6.21 \mathrm{~min}^{-1}$ torr ${ }^{-1}$ ) in the 16 control subjects. This fourfold variation in SVR provided further evidence of the considerable constitutional variability of respiratory chemosensitivity in healthy subjects (Schaefer, 1958; Lambertsen, 1960). Breath-holding time at any given level of hypercapnia was longer in subjects with low SVR values than in those with high values. The reciprocal relationship between breath-holding time and SVR is shown in Fig. 2; the breath holds were begun after rebreathing had raised the alveolar $P_{\mathrm{CO}_{2}}$ to $6.38-6.65 \mathrm{kPa}$ $(48-50 \mathrm{mmHg})$ and the inverse correlation of breath-holding time with SVR $(r=0.89)$ was highly significant $(P<0.001)$. It was also found that $\log$ BHT declined less steeply with rising $\mathrm{PCO}_{2}$ in subjects with high SVR values than in those with low SVR values. Thus, as shown in

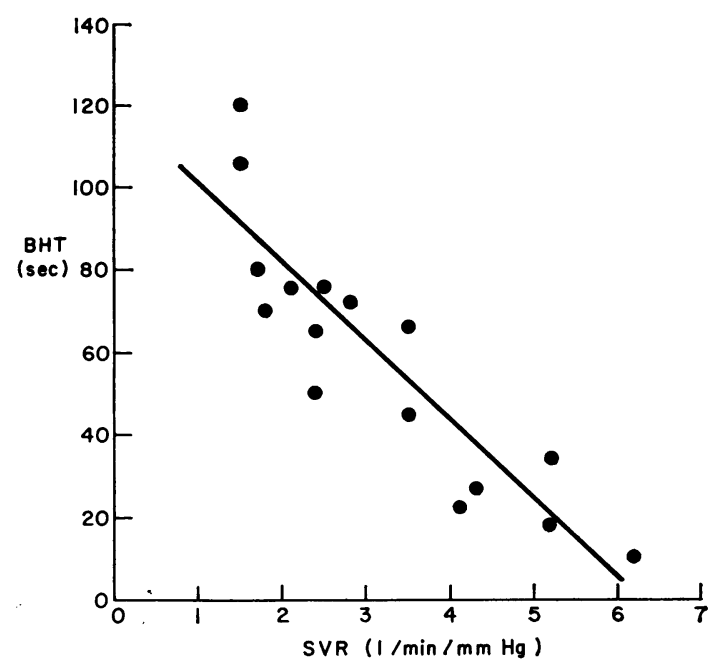

FIG. 2. Relationship between breath-holding time (BHT) and the ventilation $\mathrm{CO}_{2}$ response (SVR) in 16 control subjects. The breath holds were begun after rebreathing had raised the alveolar $\mathrm{PCO}_{2}$ to 6.4-6.7 $\mathrm{kPa}(48-50 \mathrm{mmHg})$. There was a close inverse correlation between $B H T$ and SVR $(r=-0.89, P<0.001)$. Conversion: Traditional units to SI-SVR: $1 \mathrm{lmin}^{-1}$ torr $^{-1} \approx 0.133 \mathrm{lmin}^{-1} \mathrm{kPa}^{-1}$.

Fig. 3, the $\triangle \mathrm{PCO}_{2}$ halving BHT was inversely correlated with the value of SVR $(r=0.072, P<0.01)$.

PATIENTS WITH CHRONIC AIRWAYS OBSTRUCTION AND IDIOPATHIC HYPOVENTILATION SYNDROME

VENTILATORY DATA The Table gives the mean values ( \pm SE) of the static and dynamic lung volumes, blood gases, and slopes of the ventilation 


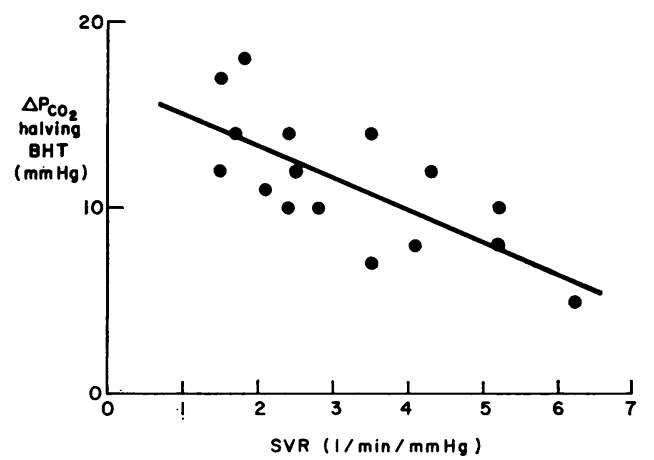

FIG. 3. Relationship between the increment in $\mathrm{PCO}_{2}$ $\left(\triangle \mathrm{PCO}_{2}\right)$ required to halve breath-holding time $(\mathrm{BHT})$ and the ventilation $\mathrm{CO}_{2}$ response (SVR) in 16 healthy subjects. The $\triangle \mathrm{PCO}_{2}$ halving $\mathrm{BHT}$ was inversely correlated with the $S V R(\tau=-0.72, P<0.01)$. Conversion: Traditional units to SI-SVR: $1 \mathrm{l} \mathrm{min}^{-1}$ torr $^{-1} \approx 0.133 \mathrm{lmin}^{-1} \mathrm{kPa}^{-1}$.

$\mathrm{CO}_{2}$ response in the patients. More detailed information can be obtained from the authors if required. The degree of airway obstruction was variable in the 17 randomly selected patients with chronic airways obstruction; their $\mathrm{FEV}_{1}$ values ranged from 0.59 to 2.48 litres. Four were mildly hypercapnic (arterial $\mathrm{PCO}_{2} 6 \cdot 38-7 \cdot 18 \mathrm{kPa}(48-54$ $\mathrm{mmHg}$ )) due to severe airway obstruction, since each had an $\mathrm{FEV}_{1}$ of less than 0.9 litres which is commonly associated with $\mathrm{CO}_{2}$ retention (Burrows, Strauss, and Niden, 1965). Five of the normocapnic patients had previously been hypercapnic, but this had occurred only transiently during an acute obstructive episode due to bronchopulmonary infection. The arterial $\mathrm{PCO}_{2}$ was increased in all five cases of idiopathic hypoventilation syndrome and their $\mathrm{FEV}_{1}$ values $(1 \cdot 8-3 \cdot 1$ litres) were much higher than in the hypercapnic patients with severe chronic airways obstruction.

Compared with the control subjects SVR was reduced $\left(<1.251 \mathrm{~min}^{-1} \mathrm{kPa}^{-1} ;<1.51 \mathrm{~min}^{-1}\right.$ torr $\left.{ }^{-1}\right)$ in 13 out of the 17 patients with chronic airways obstruction. The mean SVR in the patients wit idiopathic hypoventilation syndrome $(2.11 \mathrm{~min}-\overrightarrow{0}$ $\mathrm{kPa}^{-1} ; 0.281 \mathrm{~min}^{-1}$ torr $^{-1}$ ) was less than in the patients with chronic airways obstruction $(7.5 \overline{\bar{\phi}}$ $\min ^{-1} \mathrm{kPa}^{-1} ; 1.01 \mathrm{~min}^{-1}$ torr $^{-1}$ ), but the SVR value in the two patient groups overlapped and three of the patients with chronic airways obstruction had SVR values as low as in the cases of idiopathie hypoventilation syndrome. This demonstrated the non-specificity of the ventilation $\mathrm{CO}_{2}$ response as a test of respiratory chemosensitivity in the presence of airway obstruction.

BHT/PCO, RELATIONSHIP Figure 4 shows the relais tionship of $\log$ BHT plotted against $\mathrm{PCO}_{2}$ in breath holds made at various degrees of hypercapnia $b f$ the patients with chronic airways obstruction and idiopathic hypoventilation syndrome. The patients with chronic airways obstruction are divided int $\overline{\mathrm{B}}$ three groups; group A were normocapnic, groupt B were also normocapnic but had a previous record of hypercapnia, and group $C$ were hypercapnic at the time of study. A normal range foo the $\mathrm{BHT} / \mathrm{PCO}_{2}$ relationship was constructed fron 78 breath holds made by the 16 healthy contro subjects. Except in two patients with reduce 8 breath-holding time the $\mathrm{BHT} / \mathrm{PCO}_{2}$ points in a subgroups of the patients with chronic airway $\vec{E}$ obstruction lay within the normal range. Als $\overrightarrow{\widehat{\theta}}$ there was a normal decline of breath-holding time in response to an increase in the $\mathrm{PCO}_{2}$ at the star? of breath holding. In contrast, the $\mathrm{BHT} / \mathrm{PCO}$ points in patients with the idiopathic hypoventila tion syndrome were displaced above and to the right of the normal range, except in one breat hold begun in mild hypercapnia by patient 22 . Also the slopes of the $\log \mathrm{BHT} / \mathrm{PCO}_{2}$ lines linking the pairs of $\mathrm{BHT} / \mathrm{PCO}_{2}$ points were less steep than in the control subjects or in the cases of chronio airways obstruction. These findings suggested that breath-holding time in hypercapnia was prolonge本. and that its sensitivity to the $\mathrm{PCO}_{2}$ stimulus was rêิ

T A B L E

PULMONARY FUNCTION DATA IN THE PATIENTS

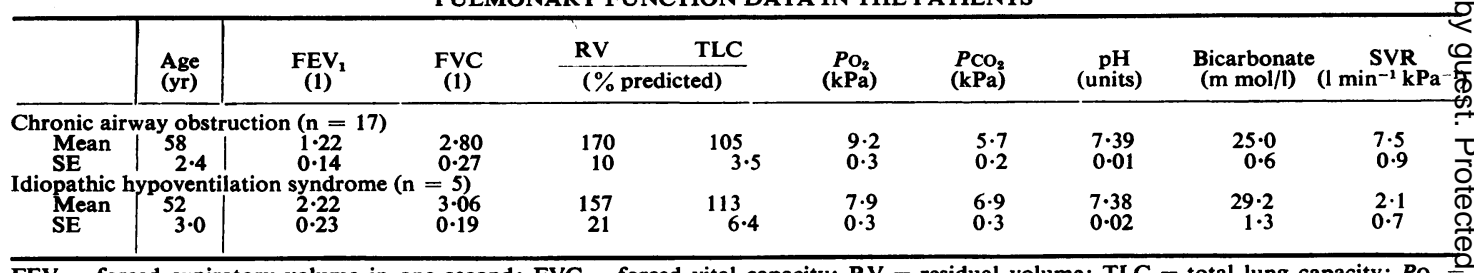

$\mathrm{FEV}_{1}=$ forced expiratory volume in one second; $\mathrm{FVC}=$ forced vital capacity; $\mathrm{RV}=$ residual volume; TLC $=$ total lung capacity; $P \mathrm{O}_{2}=$ arterial $\mathrm{O}_{2}$ tension; $\mathrm{PCO}_{2}=$ arterial $\mathrm{CO}_{2}$ tension; $\mathrm{SVR}=$ slope of the ventilation $\mathrm{CO}_{2}$ response.

Conversion: SI to Traditional Units-PCO $, P_{2}: 1 \mathrm{kPa} \approx 7.5$ torr; 


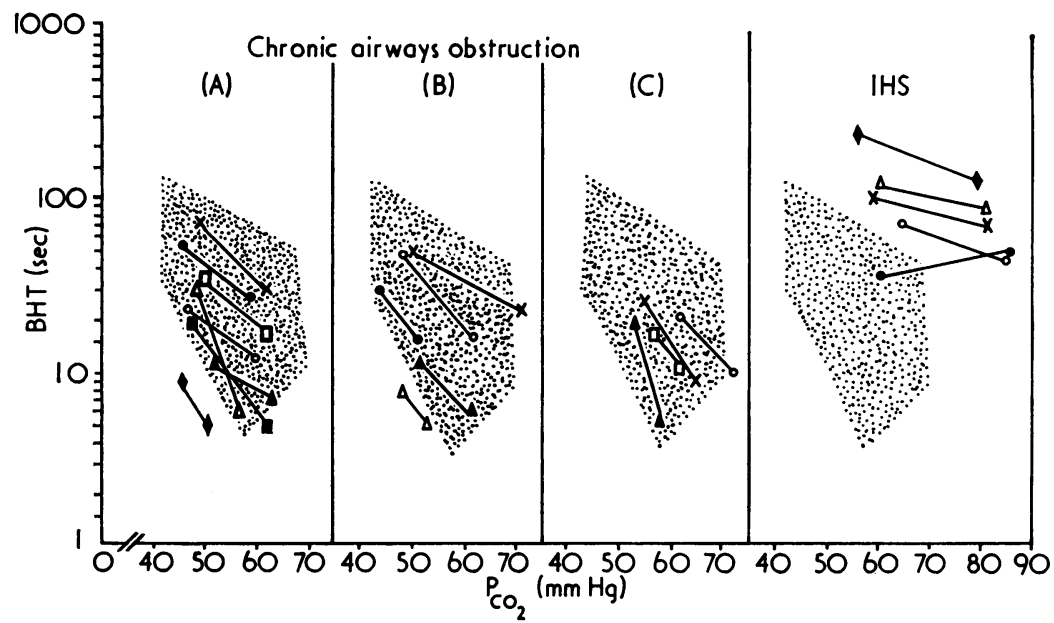

FIG. 4. Relationship between breath-holding time (BHT) and $\mathrm{PCO}_{2}$ plotted on semilogarithmic paper in 17 patients with chronic airways obstruction and five cases of the idiopathic hypoventilation syndrome (IHS). The symbols indicate pairs of breath holds made at different $\mathrm{PCO}_{2}$ levels by individual patients, and the shaded areas indicate the normal range of the $\mathrm{BHT} / \mathrm{PCO}_{2}$ relationship. The patients with chronic airways obstruction are in three groups: $A$ were normocapnic; $B$ were also normocapnic but had a previous record of hypercapnia; and $C$ were hypercapnic at the time of study. Note the normal $\mathrm{BHT} / \mathrm{PCO}_{2}$ relationship in the obstructed patients, but the prolonged breathholding time and the flattening of the log $\mathrm{BHT} / \mathrm{PCO}_{2}$ slope in the cases of idiopathic hypoventilation syndrome. Conversion: Traditional units to $\mathrm{SI}-\mathrm{PCO}_{2}: 1 \mathrm{mmHg} \approx$ $7 \cdot 5 \mathrm{kPa}$.

duced in patients with a depression in the $\mathrm{CO}_{2}$ responsiveness of the respiratory centres. Slightly increased levels of serum bicarbonate were an insufficient explanation for the altered $\mathrm{BHT} / \mathrm{PCO}_{2}$ relationship in the patients with the idiopathic hypoventilation syndrome since they were equally high in the hypercapnic obstructed patients with normal breath-holding time.

\section{DISCUSSION}

Respiratory drive of chemical origin is known to influence breath-holding time, since this is shortened when the breath is held during hypoxia (Engel et al., 1946) or hypercapnia (Godfrey and Campbell, 1969). Reduction of breath-holding time has previously been used to detect the increased chemical drive caused by hypoxia at high altitude (Douglas et al., 1913; Rahn et al., 1953). The present study has examined whether breathholding time can also be used to assess respiratory chemosensitivity even in the presence of airway obstruction. Breath-holding time in hypercapnia and the slope of a $\log \mathrm{BHT} / \mathrm{PCO}_{2}$ plot were found to depend on respiratory chemosensitivity in healthy subjects, as judged by the ventilatory response to $\mathrm{CO}_{2}$. Unlike the ventilation $\mathrm{CO}_{2}$ response, these measurements of the $\mathrm{BHT} / \mathrm{PCO}_{2}$ relationship were usually normal in patients with chronic airways obstruction, even when they had $\mathrm{CO}_{2}$ retention. In patients with the idiopathic hypoventilation syndrome there was a prolongation of breath-holding time and a flattening of the $\log \mathrm{BHT} / \mathrm{PCO}_{2}$ plot, as well as an alteration in the ventilatory response to $\mathrm{CO}_{2}$. The findings suggest that the $\mathrm{BHT} / \mathrm{PCO}_{2}$ relationship in co-operative patients may allow a more satisfactory discrimination between depressed chemosensitivity and airway obstruction as causes of hypercapnia than the measurement of the ventilation $\mathrm{CO}_{2}$ response alone.

Respiratory sensitivity to $\mathrm{CO}_{2}$ is usually evaluated by the change in some index of respiratory drive, such as ventilation, produced by a known increment in the $\mathrm{PCO}_{2}$ stimulus. Theoretically the slope of the $\log \mathrm{BHT} / \mathrm{PCO}_{\text {: }}$ plot should therefore provide a better measure of chemosensitivity than isolated measurements of $\mathrm{BHT}$ at known $\mathrm{PCO}_{2}$ levels. Thus, in physiological experiments using healthy subjects willing to make several breath holds, it is probably desirable to construct a log BHT/PCO, plot if chemosensitivity is to be as- 
sessed. In practice, however, isolated measurements of breath-holding time in hypercapnia may provide useful clinical evidence of impaired chemosensitivity, since prolonged breath-holding time in hypercapnia was such a consistent feature in the cases of idiopathic hypoventilation syndrome. Also, while detection of impaired chemosensitivity using the breath-holding technique might sometimes be obscured by lack of volition, it is unlikely that a patient with normal chemosensitivity could deliberately prolong breathholding time and thereby falsely suggest the diagnosis of idiopathic hypoventilation syndrome.

There are several advantages in evaluating the $\mathrm{BHT} / \mathrm{PCO}_{2}$ relationship by breath holding in the course of rebreathing an $\mathrm{O}_{2}-\mathrm{CO}_{2}$ gas mixture; some of these have been discussed previously by Godfrey and Campbell (1969). In brief, the preliminary breaths raise the $\mathrm{Po}_{2}$ sufficiently to eliminate the complicating effects of hypoxic drive on breath-holding time and bring the $\mathrm{PCO}_{2}$ into approximate equilibrium within the rebreathing bag, lungs, arterial blood, and brain tissue (Read and Leigh, 1967). Thus inspiration before breath holding does not dilute the alveolar $\mathrm{PCO}_{2}$, and the end-tidal $\mathrm{PCO}_{2}$ also closely represents the effective chemical stimulus at both the peripheral and central chemoreceptors-even in chronic airways obstruction when end-tidal and arterial $\mathrm{PCO}_{2}$ may be widely different while breathing ambient air. Once this equilibrium is established the $\mathrm{PCO}_{2}$ rises linearly with time: its effect on breath-holding time in the resting state can then be described equally well in terms of the initial as the breaking point $\mathrm{PCO}_{2}$ since the difference between these $\mathrm{PCO}_{2}$ values and breath-holding time itself become dependent variables. Finally, breath-holding time may be used most effectively as a test of chemosensitivity when the subject is hypercapnic. Besides the chemical stimulus to $\mathrm{PCO}_{2}$, neural stimuli from the lungs (Guz et al., 1966) and respiratory muscles (Campbell et al., 1969) also contribute to the drive to terminate a breath hold. Thus breath-holding time will tend to be a more selective measure of a subject's sensitivity to the $\mathrm{CO}_{2}$ stimulus if the breath is held at a high $\mathrm{PCO}_{2}$.

The special merit of assessing respiratory chemosensitivity by the breath-holding technique in conjunction with the conventional ventilation $\mathrm{CO}_{2}$ response is that airway obstruction does not alter the relationship of breath-holding time to $\mathrm{PCO}_{2}$. This has previously been demonstrated using healthy subjects breathing through external resistances (Clark and Godfrey, 1969) and was confirmed by the normal $\mathrm{BHT} / \mathrm{PCO}_{2}$ relationship in

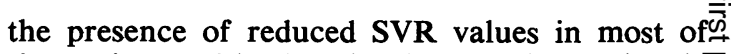
the patients with chronic airways obstruction in? the present series. Mechanical obstruction to air-음 flow has been regarded as the primary cause of $\mathrm{CO}_{2}$ retention in chronic airways obstruction@ (Baldwin, Cournand, and Richards, 1949; Burrows, Strauss, and Niden, 1965). This was supported by the normal $\mathrm{BHT} / \mathrm{PCO}_{2}$ relationship in the four patients with hypercapnia in Figure $4 \vec{w}$ However, individual cases of chronic airways ob struction may be further predisposed to hyper $\vec{x}$ capnia if they also have low levels of respiratoryen chemosensitivity due either to constitutionafu causes (Lambertsen, 1960) or to acquired factorsis such as occur in certain forms of metabolic alkalosis (Goldring et al., 1968). Likewise, some degree of obstruction is frequently present in cases of theidiopathic hypoventilation syndrome (McNicoE and Pride, 1965; Rhoads and Brody, 1969), which may accentuate their $\mathrm{CO}_{2}$ retention, although this is primarily due to loss of chemosensitivity. When disorders of chemosensitivity and lung mechanics coexist in a patient with $\mathrm{CO}_{2}$ retention it is desire able to identify the principal defect as a guide to therapy. Established techniques for assessin chemosensitivity in the presence of airway ob $\frac{\mathcal{Q}}{\mathbb{Q}}$ struction are technically difficult; they involve measuring the changes of inspiratory work rat $\vec{E}$ (Brodovsky et al., 1960; Milic-Emili and Tyler 1963) or diaphragm electromyographic activit (Lourenço and Miranda, 1968) during $\mathrm{CO}_{2}$ inhala? tion. It may therefore be gratifying to the clinicia that supporting evidence for impaired chemosen sitivity in the presence of obstructed breathing may be obtained by such a simple procedure as holding the breath.

This work was supported in part by a grant from the National Heart and Lung Institute, National Institutes of Health (HL-08805).

\section{REFERENCES}

Baldwin, E. F., Cournand, A., and Richards, D. Wิ (1949). Pulmonary insufficiency. III. A study of 122 cases of chronic pulmonary emphysema. Medicine, 28, 201.

Boren, H. G., Kory, R. C., and Syner, J. C. (1966\% Veterans Administration Army cooperative study of pulmonary function. II. Lung volume and its subdivisions in normal men. American Journal \& Medicine, 41, 96.

Brodovsky, D., Macdonell, J. A., and Cherniac席 R. M. (1960). The respiratory response to carboin dioxide in health and emphysema. Journal Clinical Investigation, 39, 724. 
Burrows, B., Strauss, R. H., and Niden, A. H. (1965). Chronic obstructive lung disease. III. Interrelationships of pulmonary function data. American Review of Respiratory Diseases, 91, 861.

Campbell, E. J. M., Godfrey, S., Clark, T. J. H., Freedman, S., and Norman, J. (1969). The effect of muscular paralysis induced by tubocurarine on the duration and sensation of breath-holding during hypercapnia. Clinical Science, 36, 323.

Cherniack, R. M. and Snidal, D. P. (1956). The effect of obstruction to breathing on the ventilatory response to $\mathrm{CO}_{2}$. Journal of Clinical Investigation, $35,1286$.

Clark, T. J. H. and Godfrey, S. (1969). The effect of $\mathrm{CO}_{2}$ on ventilation and breath-holding during exercise and while breathing through an added resistance. Journal of Physiology, 201, 551.

Douglas, C. G., Haldane, J. S., Henderson, Y., and Schneider, E. C. (1913). Physiological observations made on Pike's Peak, Colorado, with special reference to adaptation to low barometric pressure. Philosophical Transactions Series B, 203, 185.

Engel, G. L., Ferris, E. B., Webb, J. P., and Stevens, C. D. (1946). Voluntary breath-holding. II. The relation of the maximum time of breath-holding to the oxygen tension of the inspired air. Journal of Clinical Investigation, 25, 729.

Godfrey, S. and Campbell, E. J. M. (1969). Mechanical and chemical control of breath-holding. Quarterly Journal of Experimental Physiology, 54, 117.

Goldring, R. M., Cannon, P. J., Heinemann, H. O., and Fishman, A. P. (1968). Respiratory adjustment to chronic metabolic alkalosis in man. Journal of Clinical Investigation, 47, 188.

Guz, A., Noble, M. I. M., Widdicombe, J. G., Trenchard, D., Mushin, W. W., and Makey, A. R. (1966). The role of the vagal and glossopharyngeal afferent nerves in respiratory sensation, control of breathing and arterial pressure regulation in conscious man. Clinical Science, $30,161$.

Hill, L. and Flack, M. (1908). The effect of excess of carbon dioxide and of want of oxygen upon the respiration and the circulation. Journal of Physiology, 37, 77
Kory, R. C., Callahan, R., Boren, H. G., and Syner, J. C. (1961). Veterans Administration Army cooperative study of pulmonary function. I. Clinical spirometry in normal men. American Journal of Medicine, 30, 243.

Lambertsen, C. J. (1960). Carbon dioxide and respiration in acid-base homeostasis. Anesthesiology, 21, 642 .

Lourenço, R. V., Cherniack, N. S., Malm, J. R., and Fishman, A. P. (1966). Nervous output from the respiratory center during obstructed breathing. Journal of Applied Physiology, 21, 527.

and Miranda, J. M. (1968). Drive and performance of the ventilatory apparatus in chronic obstructive lung disease. New England Journal of Medicine, 279, 53.

McNicol, M. W. and Pride, N. B. (1965). Unexplained underventilation of the lungs. Thorax, 20, 53.

Milic-Emili, J. and Tyler, J. M. (1963). Relation between work output of respiratory muscles and end-tidal $\mathrm{CO}_{2}$ tension. Journal of Applied Physiology, 18, 497.

Rahn, H., Bahnson, H. T., Muxworthy, J. F., and Hagen, J. M. (1953). Adaptation of high altitude: changes in breath-holding time. Journal of Applied Physiology, 6, 154.

Read, D. J. C. and Leigh, J. (1967). Blood-brain tissue $\mathrm{PCO}_{2}$ relationships and ventilation during rebreathing. Journal of Applied Physiology, 23, 53.

Rhoads, G. G. and Brody, J. S. (1969). Idiopathic alveolar hypoventilation: clinical spectrum. Annals of Internal Medicine, 71, 271.

Schaefer, K. E. (1958). Respiratory pattern and respiratory response to $\mathrm{CO}_{2}$. Journal of Applied Physiology, 13, 1.

Siggaard-Andersen, O. (1963). Blood acid-base alignment nomogram. Scandinavian Journal of Clinical and Laboratory Investigation, 15, 211.

Requests for reprints to: Dr. N. N. Stanley, Department of Medicine, The Middlesex Hospital, London W1P 7PN. 